\title{
Clinicopathological characteristics and long-term prognosis of screening detected non-palpable breast cancer by ultrasound in hospital-based Chinese population (2001-2014)
}

\author{
Bo Pan ${ }^{1, *}$, Ru Yao ${ }^{1, *}$, Qing-Li Zhu ${ }^{2, *}$, Chang-Jun Wang ${ }^{1}$, Shan-Shan You ${ }^{2}$, Jing \\ Zhang $^{2}$, Qian-Qian Xu' ${ }^{1}$, Feng Cai ${ }^{3}$, Jie Shi ${ }^{4}$, Yi-Dong Zhou ${ }^{1}$, Feng Mao ${ }^{1}$, Yan Lin ${ }^{1}$, \\ Jing-Hong Guan ${ }^{1}$, Song-Jie Shen ${ }^{1}$, Zhi-Yong Liang ${ }^{4}$, Yu-Xin Jiang ${ }^{2}$, Qiang Sun ${ }^{1}$

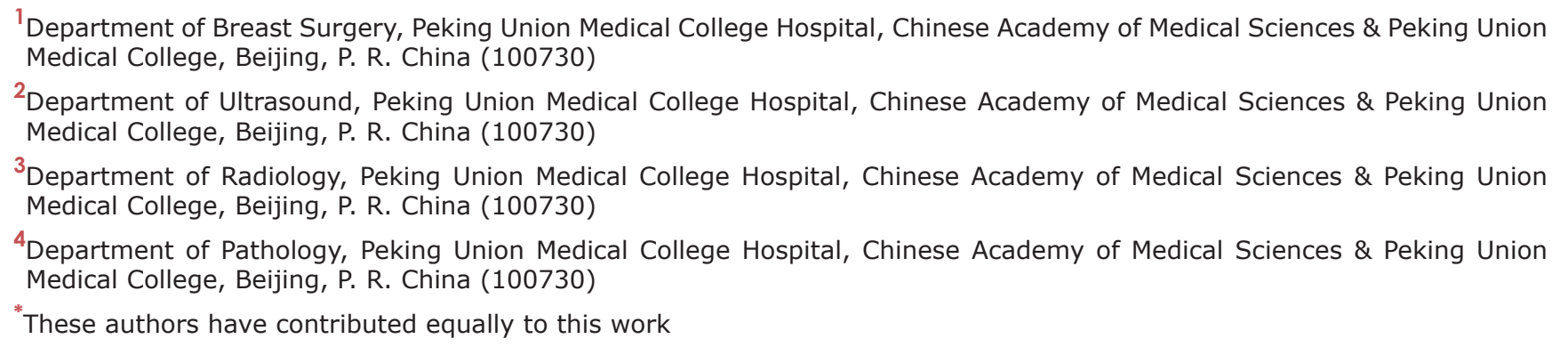 \\ Correspondence to: Qiang Sun, email: sunqiang_pumc@163.com
}

Keywords: non-palpable breast cancer, screening, ultrasound, prognosis

Received: August 01,2016 Accepted: September 12, $2016 \quad$ Published: September 28, 2016

\section{ABSTRACT}

Purpose: The mainstay modality of breast cancer screening in China is the hospital-based opportunistic screening among asymptomatic self-referred women. There is little data about the ultrasound (US) detected non-palpable breast cancer (NPBC) in Chinese population.

Methods: We analyzed 699 consecutive NPBC from 1.8-2.3 million asymptomatic women from 2001 to 2014, including 572 US-detected NPBC from 3,786 US-positive women and 127 mammography (MG) detected NPBC from 788 MG-positive women. The clinicopathological features, disease-free survival (DFS) and overall survival (OS) were compared between the US- and MG-detected NPBC. Prognostic factors of NPBC were identified.

Results: Compared to MG, US could detect more invasive NPBC $(83.6 \%$ vs $54.3 \%, p<0.001)$, lymph node positive NPBC $(19.1 \%$ vs $10.2 \%, p=0.018)$, lower grade $(24.8 \%$ vs $16.5 \%$, $\mathrm{p}<0.001)$, multifocal $(19.2 \%$ vs $6.3 \%, \mathrm{p}<0.001)$, PR positive (71.4\% vs $66.9 \%, p=0.041)$, Her2 negative (74.3\% vs $54.3 \%, p<0.001)$, Ki67 high (defined as $>14 \%, 46.3 \%$ vs $37.0 \%, p=0.031$ ) cancers and more NPBC who received chemotherapy $(40.7 \%$ vs $21.3 \%, p<0.001)$. There was no significant difference in 10-year DFS and OS between US-detected vs MG-detected NPBC, DCIS and invasive NPBC. For all NPBC and the US-detected NPBC, the common DFS-predictors included pT, pN, p53 and bilateral cancers.

Conclusion: US could detect more invasive, node-positive, multifocal NPBC in hospital-based asymptomatic Chinese female, who could achieve comparable 10-year DFS and OS as MG-detected NPBC. US would not delay early detection of NPBC with improved cost-effectiveness, thus could serve as the feasible initial imaging modality in hospital-based opportunistic screening among Chinese women.

\section{INTRODUCTION}

Breast cancer is now the most common cancer in Chinese women, and the leading cause of cancer death in women younger than 45 years $[1,2]$. Chinese women usually have smaller and denser breasts compared to Caucasian counterparts $[1,3,4]$, which would reduce the diagnostic accuracy of mammography (MG) [5]. 
The younger median age at breast cancer diagnosis in Chinese women compared with females in high-income countries also makes MG less effective in breast cancer detection [6, 7]. Given the huge population in China with its geographic diversity, urban rural disparity, and the demographic epidemiology of developing breast cancer, screening strategy might be different from the annual/ biennial mammographic screening in the Western world. The current mainstay modality of breast cancer early detection in China is the hospital-based opportunistic screening among asymptomatic self-referred women.

Milestone studies showed that ultrasound (US) was not only a useful supplementary imaging tool of MG for women with dense breast or elevated risk [8-14], but an effective primary screening test for breast cancer both in the western world and in China [7, 15-18]. US was widely used as initial imaging test for breast detection in hospitals in China, and also designated as the primary screening tool in the standard protocol of the Two Cancers Screening Project jointly launched by the National Health and Family Planning Commission (former Ministry of Health of China) and the All-China Women's Federation [19-22]. However, there is little data about the specific features and prognosis of the US-detected non-palpable breast cancer (NPBC) in hospital-based Chinese population. Thus, we performed this study to compare the clinicopathological characteristics and the long-term survival of US-detected and MG-detected NPBC in Chinese women.

\section{RESULTS}

\section{Descriptive information of the study cohort}

A total of 4,574 patients with positive screening imaging test (defined as BI-RADS 4 and 5) underwent biopsies, including 3,786 US-guided biopsies and 788 MG-guided biopsies as described in METHOD. 729 NPBC were diagnosed with 588 US-detected NPBC and 141 MG-detected NPBC, thus the positive predictive value (PPV) of US-guided biopsy was $15.5 \%$ and the PPV of MG-guided biopsy was $17.9 \%$. After excluding 16 US-NPBC patients and 14 MG-NPBC patients whose clinicopathological information were missing, 699 NPBC patients including 572 US-NPBC and 127 MGNPBC were analyzed in the study, comprising $7.9 \%$ of contemporary 8,821 breast cancer treated in PUMC Hospital. 680 patients $(97.3 \%)$ were treated during the recent ten years $(2005-2014)$ while 551 patients $(78.8 \%)$ were treated during the recent five years (2010-2014). 462 patients (66.1\%) were pre-menopausal and 237 (33.9\%) post-menopausal. With a median follow-up time of 36 months (6-163 months, mean 42 months), 32 patients including 27 US-NPBC and 5 MG-NPBC developed recurrence or metastasis. Nine patients who were all detected by US passed away including 6 breast cancer related deaths and 3 deaths due to other cause (Figure 1).

\section{Comparison of clinicopathological characteristics between US detected NPBC and MG-detected NPBC}

Compared to MG, US could detect more invasive NPBC (83.6\% vs 54.3\%, p <0.001), lymph node positive cancer $(19.1 \%$ vs $10.2 \%, \mathrm{p}=0.018)$, low grade cancer $(24.8 \%$ vs $16.5 \%, \mathrm{p}<0.001)$, multifocal cancer $(19.2 \%$ vs $6.3 \%, \mathrm{p}<0.001)$, PR positive cancer $(71.4 \%$ vs $66.9 \%$, $\mathrm{p}=0.041)$, Her2 negative cancer $(74.3 \%$ vs $54.3 \%$, $\mathrm{p}<0.001$ ), Ki67 high cancer (defined as $>14 \%, 46.3 \%$ vs $37.0 \%, \mathrm{p}=0.031$ ) and more NPBC which needed chemotherapy $(40.7 \%$ vs $21.3 \%, \mathrm{p}<0.001)$. There was no significant difference between these two groups of NPBC in age, lymphovascular invasion (LVI), laterality, surgery, radiotherapy, and anti-Her2 targeted therapy (Table 1).

\section{Survival outcomes and prognostic factors of NPBC}

The 10-year Kaplan-Meier estimated disease free survival (DFS) of all NPBC patients, US-NPBC and MGNPBC were $91.0 \%, 90.6 \%$ and $92.7 \%$, whereas the 10 year overall survival (OS) were 96.9\%, 96.1\% and 100.0\% respectively. As for the ductal carcinoma in situ (DCIS), the 10-year Kaplan-Meier estimated DFS of US-DCISNPBC and MG-DCIS-NPBC were $100.0 \%$ and $93.8 \%$, whereas the 10 -year OS were both $100.0 \%$. The 10 -year Kaplan-Meier estimated DFS of invasive US-NPBC and invasive MG- NPBC were $88.6 \%$ and $92.0 \%$, whereas the 10 -year OS were $95.2 \%$ and $100.0 \%$ respectively. There was no significant difference in 10-year DFS or OS between US- and MG-detected NPBC, between US- and MG-detected DCIS or between US- and MG-detected invasive NPBC (Figure 2, Table 2).

DFS prognostic factor for both all NPBC included pT $(\mathrm{p}=0.018), \mathrm{pN}(\mathrm{p}=0.040)$, laterality (also bilateral cancers, $\mathrm{p}<0.001)$ and $\mathrm{p} 53$ status $(\mathrm{p}=0.010)$ (Table 3 ), and these same four factors were also identified as the DFS related factors for US-detected NPBC (Table 4). LVI, $\mathrm{ER}, \mathrm{PR}$, hormone receptor status, immunophenotype, chemotherapy and endocrine therapy might be potential DFS predictors for both all NPBC and US-detected NPBC according to univariate analysis. However, these factors were not significant in the multivariate analysis. None of the clinicopathological and treatment factors listed above could serve as MG-NPBC DFS factors, or as OS predictors due to the limited events.

\section{DISCUSSION}

Breast cancer incidence has increased rapidly in the past two decades and is now the most common cancer among women in China. Given the immense scale of the Chinese population with diversity, study showed that it might take 40 years to screen each woman 
in the target age group once [2]. The former Ministry of Health of China and All-China Women's Federation jointly launched a 3-year (2009-2011) national project which provided free breast cancer screening for 1.46 million rural women aged $35-59$ years [7, 19-22]. The 3-year second phase (2012-2015) of this project was to provide free breast cancer screening for 6 million rural women aged 35-64 years [7, 23]. Six million women was a huge screening cohort, however, it only comprised $0.90 \%$ (6 million/667.03 million) of all female in China.

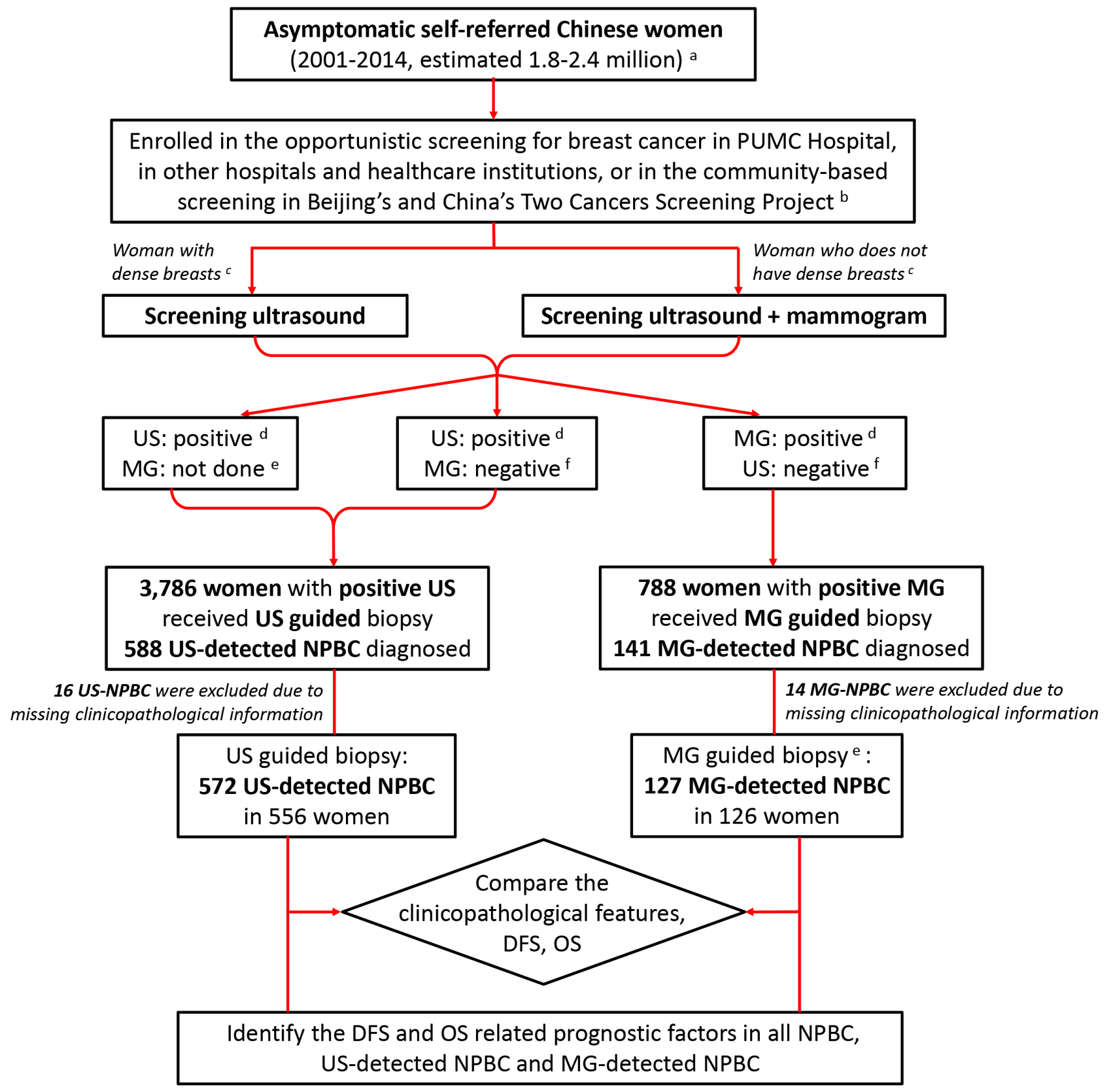

Figure 1: Diagram of the research design. Asymptomatic Chinese women were screened to detect non-palpable breast cancer (NPBC). The clinic-pathological characteristics, disease free survival (DFS) and overall survival (OS) were compared between ultrasound (US) detected NPBC and mammogram (MG) detected NPBC. DFS and OS related prognostic factors of all NPBC, US-detected and MG-detected NPBC were identified. A. The total 1.8-2.4 million asymptomatic women participated in the hospital-based screening was estimated with the 699 screen-detected NPBC and the incidence of 30-40/ten thousand. B. The Beijing's Two Cancers Screening Project had screened breast cancer with physical examination (PE) and ultrasound in a combination of community-based and hospital-based manner. Part of the women with positive screening ultrasound cases had been transferred and treated in PUMC Hospital. C. Dense breasts were defined as BI-RADS category 3 and 4 (edition 2003), or C and D (edition 2013). D. Positive imaging study of US and MG was defined as BI-RADS 4 and 5. E. Some women would refuse mammogram due to the minor radioactivity or the extra expensed, or because it would be painful to perform for small breasts. F. Negative imaging study of US and MG was defined as BI-RADS 1, 2 and 3. 
Table 1: Clinicopathological characteristics of screening-detected NPBC from hospital-based population

\begin{tabular}{|c|c|c|c|}
\hline \multirow{2}{*}{ Characteristics } & \multicolumn{2}{|c|}{ No. (\%) of Patients } & \multirow{2}{*}{$\mathbf{P}^{\mathbf{a}}$} \\
\hline & US-NPBC & MG-NPBC & \\
\hline Total & 572 & 127 & \\
\hline \multicolumn{4}{|l|}{ Age (years) } \\
\hline $\operatorname{Mean} \pm$ SD & $51.33 \pm 12.67$ & $50.29 \pm 11.53$ & 0.396 \\
\hline Age at diagnosis & & & 0.065 \\
\hline$<40$ & $96(16.8)$ & $14(11.0)$ & \\
\hline $40 \sim 49$ & $192(33.6)$ & $56(44.1)$ & \\
\hline $50 \sim 59$ & $140(24.5)$ & $33(26.0)$ & \\
\hline$\geq 60$ & $144(25.1)$ & $24(18.9)$ & \\
\hline Tumor histology & & & 0.000 \\
\hline DCIS NPBC & $94(16.4)$ & $58(45.7)$ & \\
\hline Invasive NPBC & $478(83.6)$ & $69(54.3)$ & \\
\hline pT & & & 0.000 \\
\hline Tis & $94(16.4)$ & $58(45.7)$ & \\
\hline T1a & $82(14.3)$ & $29(22.8)$ & \\
\hline $\mathrm{T} 1 \mathrm{~b}$ & $141(24.7)$ & $14(11.0)$ & \\
\hline $\mathrm{T} 1 \mathrm{c}$ & $208(36.4)$ & $19(15.0)$ & \\
\hline $\mathrm{T} 2$ & $47(8.2)$ & $7(5.5)$ & \\
\hline Lymph node status & & & 0.018 \\
\hline Negative & $463(80.9)$ & $114(89.8)$ & \\
\hline Positive & $109(19.1)$ & $13(10.2)$ & \\
\hline Number of positive $L N$ & & & 0.378 \\
\hline $\operatorname{Mean} \pm$ SD & $1.03 \pm 3.78$ & $0.70 \pm 3.66$ & \\
\hline $\mathbf{p N}$ & & & 0.050 \\
\hline N0 & $463(81.0)$ & $114(89.8)$ & \\
\hline N1 & $74(12.9)$ & $7(5.5)$ & \\
\hline $\mathrm{N} 2$ & $13(2.3)$ & $4(3.1)$ & \\
\hline N3 & $22(3.8)$ & $2(1.6)$ & \\
\hline TNM stage ${ }^{\mathrm{b}}$ & & & 0.000 \\
\hline 0 & 94 (16.4) & $58(45.7)$ & \\
\hline Ia & $343(60.0)$ & $53(41.7)$ & \\
\hline $\mathrm{Ib}$ & $2(0.3)$ & $0(0.0)$ & \\
\hline IIa & 84 (14.7) & $7(5.5)$ & \\
\hline IIb & $14(2.6)$ & $3(2.4)$ & \\
\hline IIIa & $13(2.2)$ & $4(3.1)$ & \\
\hline IIIc & $22(3.8)$ & $2(1.6)$ & \\
\hline
\end{tabular}




\begin{tabular}{|c|c|c|c|}
\hline \multirow{2}{*}{ Characteristics } & \multicolumn{2}{|c|}{ No. (\%) of Patients } & \multirow{2}{*}{$\mathbf{P}^{\mathbf{a}}$} \\
\hline & US-NPBC & MG-NPBC & \\
\hline Histological grade & & & 0.000 \\
\hline Low grade & $142(24.8)$ & $21(16.5)$ & \\
\hline Medium grade & $288(50.3)$ & $59(46.5)$ & \\
\hline High grade & $111(19.4)$ & $45(35.4)$ & \\
\hline Unknown & $31(5.4)$ & $2(1.6)$ & \\
\hline Focality & & & 0.000 \\
\hline Monofocal & $462(80.8)$ & $119(93.7)$ & \\
\hline Multifocal & $110(19.2)$ & $8(6.3)$ & \\
\hline Laterality & & & 0.187 \\
\hline Unilateral & $514(89.9)$ & $109(85.8)$ & \\
\hline Bilateral & $58(10.1)$ & $18(14.2)$ & \\
\hline LVI & & & 0.642 \\
\hline No & $546(95.5)$ & $120(94.5)$ & \\
\hline Yes & $26(4.5)$ & $7(5.5)$ & \\
\hline ER & & & 0.052 \\
\hline Negative & $129(22.6)$ & $28(22.0)$ & \\
\hline Positive & $441(77.1)$ & $96(75.6)$ & \\
\hline Unknown & $2(0.3)$ & $3(2.4)$ & \\
\hline PR & & & 0.041 \\
\hline Negative & $162(28.3)$ & $39(30.7)$ & \\
\hline Positive & 408 (71.4) & $85(66.9)$ & \\
\hline Unknown & $2(0.3)$ & $3(2.4)$ & \\
\hline Hormone receptor & & & 0.051 \\
\hline Negative & $114(19.9)$ & $24(18.9)$ & \\
\hline Positive & $456(79.7)$ & $100(78.7)$ & \\
\hline Unknown & $2(0.3)$ & $3(2.4)$ & \\
\hline Her2 status & & & 0.000 \\
\hline Negative & $425(74.3)$ & $69(54.3)$ & \\
\hline Positive & $92(16.1)$ & $27(21.3)$ & \\
\hline Unknown & $55(9.6)$ & $31(24.4)$ & \\
\hline Ki67 & & & 0.031 \\
\hline$<14 \%$ & $292(51.1)$ & $72(56.7)$ & \\
\hline$\geq 14 \%$ & $265(46.3)$ & $47(37.0)$ & \\
\hline Unknown & $15(2.6)$ & $8(6.3)$ & \\
\hline
\end{tabular}




\begin{tabular}{|c|c|c|c|}
\hline \multirow{2}{*}{ Characteristics } & \multicolumn{2}{|c|}{ No. $(\%)$ of Patients } & \multirow{2}{*}{$\mathbf{P}^{\mathbf{a}}$} \\
\hline & US-NPBC & MG-NPBC & \\
\hline p53 & & & 0.023 \\
\hline Negative & $392(68.6)$ & $84(66.1)$ & \\
\hline Positive & $169(29.5)$ & $35(27.6)$ & \\
\hline Unknown & $11(1.9)$ & $8(6.3)$ & \\
\hline Immunophenotype $^{\mathrm{c}}$ & & & 0.000 \\
\hline DCIS & $94(16.4)$ & $58(45.7)$ & \\
\hline Luminal A & $176(30.8)$ & $21(16.6)$ & \\
\hline Luminal B & $183(32.1)$ & $30(23.6)$ & \\
\hline Her2 & $38(6.6)$ & $5(3.9)$ & \\
\hline TNBC & $54(9.4)$ & $4(3.1)$ & \\
\hline Unknown & $27(4.7)$ & $9(7.1)$ & \\
\hline Surgery & & & 0.488 \\
\hline Mastectomy & $448(78.3)$ & $103(81.1)$ & \\
\hline Breast conserving surgery & $124(21.7)$ & $24(18.9)$ & \\
\hline Chemotherapy & & & 0.000 \\
\hline No & $339(59.3)$ & $100(78.7)$ & \\
\hline Yes & $233(40.7)$ & $27(21.3)$ & \\
\hline Radiotherapy & & & 0.476 \\
\hline No & $464(81.1)$ & $100(78.7)$ & \\
\hline Yes & $104(18.2)$ & $27(21.3)$ & \\
\hline Unknown & $4(0.7)$ & $0(0.0)$ & \\
\hline Anti-Her2 targeted therapy & & & 0.706 \\
\hline No & $503(88.0)$ & $115(90.6)$ & \\
\hline Yes & $58(10.1)$ & $10(7.9)$ & \\
\hline Unknown & $11(1.9)$ & $2(1.5)$ & \\
\hline Endocrine therapy & & & 0.051 \\
\hline No & $119(20.9)$ & $25(19.7)$ & \\
\hline Yes & $451(78.8)$ & $99(78.0)$ & \\
\hline Unknown & $2(0.3)$ & $3(2.4)$ & \\
\hline
\end{tabular}

Abbreviations: NPBC, non-palpable breast cancer; US, ultrasound; MG, mammography; SD, standard deviation; TNM, tumor, node, metastasis system; DCIS, ductal carcinoma in situ; ER, estrogen receptor; PR, progesterone receptor; LVI, lymphovascular invasion.

${ }^{a}$ Bold type indicates statistical significance.

${ }^{b}$ TNM stage is according to the $7^{\text {th }}$ AJCC cancer staging system.

'Immunophenotype of invasive NPBC is according to the the immunohistochemical subtype of 2013 St. Gallen Consensus. 

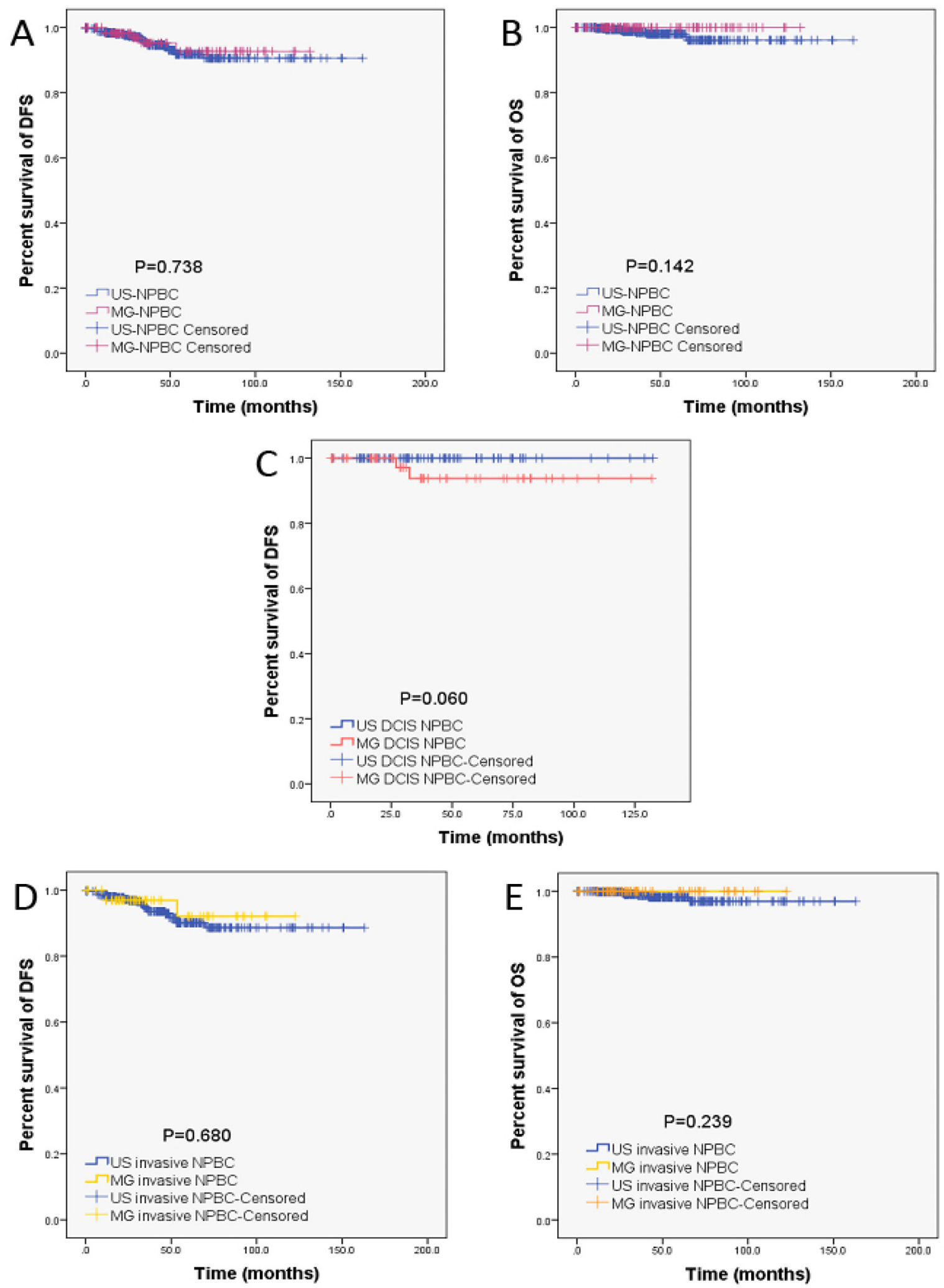

Figure 2: Kaplan-Meier estimated long-term prognosis of NPBC patients. There was no significant difference in both DFS and OS between US- and MG-detected NPBC (Figure 2A, 2B), between US- and MG-detected ductal carcinoma in situ (DCIS, Figure 2C), or between US- and MG-detected invasive NPBC (Figure 2D, 2E). Please note that the figure for comparison of US- vs MG-detected DCIS NPBC was unavailable because the OS of US- and MG-detected DCIS NPBC were both $100 \%$, with all patients alive. The US-detected NPBC could achieve similar 10-year DFS and OS compared to MG-detected counterparts. 
Table 2: Comparison of the Kaplan-Meier estimated 10-year DFS and OS between US- and MG-NPBC

\begin{tabular}{|c|c|c|c|c|c|}
\hline Patients (No.) & NPBC Group (No.) & 10-year DFS (\%) & $P$ value & 10-year OS (\%) & P value \\
\hline \multirow{2}{*}{ All (699) } & US (572) & 90.6 & \multirow{2}{*}{0.738} & 96.1 & \multirow{2}{*}{0.142} \\
\hline & MG (127) & 92.7 & & 100.0 & \\
\hline \multirow{2}{*}{ DCIS (152) } & US (94) & 100.0 & \multirow{2}{*}{0.060} & 100.0 & \multirow{2}{*}{1.000} \\
\hline & MG (58) & 93.8 & & 100.0 & \\
\hline \multirow{2}{*}{ Invasive (547) } & US (478) & 88.6 & \multirow{2}{*}{0.680} & 95.2 & \multirow{2}{*}{0.239} \\
\hline & MG (69) & 92.0 & & 100.0 & \\
\hline
\end{tabular}

Abbreviations: NPBC, non-palpable breast cancer; US, ultrasound; MG, mammography; DFS, disease free survival; OS, overall survival; DCIS, ductal carcinoma in situ.

Table 3: Univariate and multivariate Cox analysis of DFS related prognostic factors of all NPBC patients

\begin{tabular}{|c|c|c|c|}
\hline \multirow{2}{*}{ Variables } & \multirow{2}{*}{$\frac{\text { Univariate }^{\mathrm{a}}}{\mathbf{P}^{\mathrm{c}}}$} & \multicolumn{2}{|c|}{ Multivariate $^{\mathrm{b}}$} \\
\hline & & HR $(95 \%$ CI) & $\mathbf{P}^{\mathbf{c}}$ \\
\hline Screening method & 0.738 & $2.125(0.667,6.770)$ & 0.202 \\
\hline Age at diagnosis & 0.129 & $0.897(0.594,1.354)$ & 0.605 \\
\hline Histological type & 0.079 & $1.174(0.056,24.709)$ & 0.918 \\
\hline pT & 0.002 & $7.332(1.416,37.954)$ & 0.018 \\
\hline Lymph node status & 0.000 & $1.105(0.228,5.531)$ & 0.901 \\
\hline $\mathbf{p N}$ & 0.000 & $3.840(1.064,13.855)$ & 0.040 \\
\hline TNM stage ${ }^{d}$ & 0.000 & $0.350(0.060,2.040)$ & 0.243 \\
\hline Focality & 0.201 & $1.124(0.388,3.257)$ & 0.830 \\
\hline Laterality & 0.000 & $6.927(3.010,15.941)$ & 0.000 \\
\hline LVI & 0.000 & $1.793(0.602,5.341)$ & 0.294 \\
\hline ER status & 0.007 & $0.436(0.093,2.039)$ & 0.292 \\
\hline PR status & 0.002 & $0.326(0.105,1.017)$ & 0.054 \\
\hline Hormone receptor status & 0.004 & $0.000(0.000,3.285 \mathrm{E}+064)$ & 0.891 \\
\hline HER2 status & 0.215 & $0.817(0.284,2.345)$ & 0.707 \\
\hline Ki-67 expression & 0.166 & $0.830(0.371,1.856)$ & 0.650 \\
\hline p53 & 0.431 & $0.284(0.109,0.741)$ & 0.010 \\
\hline Surgery & 0.290 & $0.448(0.176,1.138)$ & 0.091 \\
\hline Immunophenotype & 0.004 & $0.803(0.452,1.429)$ & 0.456 \\
\hline Chemotherapy & 0.000 & $2.648(0.821,8.541)$ & 0.103 \\
\hline Radiotherapy & 0.358 & $0.385(0.098,1.507)$ & 0.170 \\
\hline Anti-Her 2 targeted therapy & 0.139 & $1.037(0.269,3.993)$ & 0.958 \\
\hline Endocrine therapy & 0.006 & $0.965(0.174,5.354)$ & 0.968 \\
\hline
\end{tabular}

Abbreviations: HR, hazard ratio; ER, estrogen receptor; PR, progesterone receptor.

${ }^{a}$ Kaplan-Meier univariate analysis of all factors.

${ }^{\mathrm{b}}$ Adjusted by Cox proportional hazard regression model including all factors with the method of enter.

'Bold type indicates statistical significance.

${ }^{\mathrm{d}}$ TNM stage is according to the $7^{\text {th }}$ AJCC cancer staging system.

' Immunophenotype of invasive NPBC is according to the the immunohistochemical subtype of 2013 St. Gallen Consensus. 
Table 4: Univariate and multivariate Cox analysis of DFS related prognostic factors of US-detected NPBC patients

\begin{tabular}{|c|c|c|c|}
\hline \multirow{2}{*}{ Variables } & \multirow{2}{*}{$\frac{\text { Univariate }^{\mathrm{a}}}{\mathbf{P}^{\mathrm{c}}}$} & \multicolumn{2}{|c|}{ Multivariate $^{\mathrm{b}}$} \\
\hline & & HR $(95 \%$ CI $)$ & $\mathbf{P}^{\mathbf{c}}$ \\
\hline Age at diagnosis & 0.175 & $0.998(0.642,1.551)$ & 0.993 \\
\hline Histological type & 0.052 & $0.745(0.394,1.412)$ & 0.367 \\
\hline pT & 0.001 & $27.672(4.873,157.124)$ & 0.000 \\
\hline Lymph node status & 0.000 & $0.556(0.108,2.857)$ & 0.482 \\
\hline $\mathbf{p N}$ & 0.000 & $5.771(1.608,20.710)$ & 0.007 \\
\hline TNM stage $^{d}$ & 0.000 & $0.238(0.041,1.390)$ & 0.238 \\
\hline Focality & 0.688 & $0.576(0.164,2.016)$ & 0.388 \\
\hline Laterality & 0.000 & $9.652(3.925,23.735)$ & 0.000 \\
\hline LVI & 0.000 & $2.387(0.739,7.711)$ & 0.146 \\
\hline ER status & 0.017 & $0.744(0.117,4.717)$ & 0.754 \\
\hline PR status & 0.017 & $1.088(0.196,6.049)$ & 0.923 \\
\hline Hormone receptor status & 0.002 & $0.000(0.000,9.542 \mathrm{E}+051)$ & 0.826 \\
\hline HER2 status & 0.477 & $0.748(0.218,2.565)$ & 0.644 \\
\hline Ki-67 expression & 0.309 & $1.083(0.457,2.569)$ & 0.856 \\
\hline p53 & 0.210 & $0.241(0.084,0.689)$ & 0.008 \\
\hline Immunophenotype & 0.002 & $0.699(0.401,1.218)$ & 0.206 \\
\hline Surgery & 0.614 & $0.406(0.132,1.252)$ & 0.117 \\
\hline Chemotherapy & 0.000 & $1.740(0.545,5.555)$ & 0.350 \\
\hline Radiotherapy & 0.585 & $0.158(0.023,1.113)$ & 0.064 \\
\hline Anti-Her 2 targeted therapy & 0.218 & $0.914(0.157,5.313)$ & 0.920 \\
\hline Endocrine therapy & 0.004 & $0.440(0.057,3.419)$ & 0.432 \\
\hline
\end{tabular}

Abbreviations: HR, hazard ratio; ER, estrogen receptor; PR, progesterone receptor.

${ }^{a}$ Kaplan-Meier univariate analysis of all factors.

${ }^{\mathrm{b}}$ Adjusted by Cox proportional hazard regression model including all factors with the method of enter.

'Bold type indicates statistical significance.

dTNM stage is according to the $7^{\text {th }}$ AJCC cancer staging system.

${ }^{\mathrm{e}}$ Immunophenotype of invasive NPBC is according to the the immunohistochemical subtype of 2013 St. Gallen Consensus.

With a cross-sectional assumption and estimated with the current breast cancer incidence of 30-40/ten thousand in rural areas of China, there would be approximately 1,8002,400 screening detected breast cancer to be diagnosed out of these 6 million women in one year. However, it only comprised $0.67 \%-0.89 \%$ (1,800-2,400/268.6 thousand) of all newly-diagnosed female breast cancer in 2015 [2]. In Beijing, Shanghai and other cities in China, medical insurance of various sorts would usually cover most of the expenses when asymptomatic women intentionally ask for breast physical examination and screening imaging tests in hospital. So in the current diversified breast cancer screening in China, hospital-based opportunistic screening among asymptomatic women is still the mainstay measure.
Ultrasound has the advantages of portability, inexpensiveness, nonradioactive and improved sensitivity in women with dense breasts. It is widely accepted that US is an useful supplementary tool for MG in women with dense breast or elevated risk [8-14], Berg WA et al. showed in the ACRIN 6666 trial that adding a single screening US to $\mathrm{MG}$ would yield an additional 1.1 to 7.2 breast cancers per 1000 high-risk women, also with increase of the false positives [8]. Kolb TM et al. showed that screening US could depict small, early-stage, MG-occult cancers similar in size and stage to MG-NPBC and smaller and lower in stage than palpable cancers in dense breasts [13]. Similar benefit of US as an adjunct to screening MG was reported in women with increased risk and dense breasts [11] with 15\% additional detection of the MG occult breast cancers [14] 
as well as lethal breast cancers [24]. A systematic review showed that supplemental US in women with dense breast tissue permitted detection of small, otherwise occult breast cancers. Potential adverse impact was increased biopsy rate.

Moreover, US is currently regarded as effective primary screening test for breast cancer [7, 15-18]. Benson SR et al. evaluated US as a first-line diagnostic tool and revealed that US is significantly better than MG for detecting invasive breast cancer [17]. Berg WA et al. pushed the ACRIN 6666 trial to a higher level showing that cancer detection rate with US is comparable with MG, with more invasive and node-negative cancers and more false positives $[15,16]$. A small-sample-size prospective double-blind study showed that primary US is capable of detecting NPBC in asymptomatic women at an early stage with acceptable rate of false positive [18]. In our previous studies, we showed with a multi-center randomized controlled trial that US would be the preferred imaging test for breast cancer screening in high risk Chinese women [7], and be more sensitive than MG $(100.0 \%$ vs $57.1 \%, \mathrm{P}=0.04)$ with improved diagnostic accuracy (0.999 vs 0.766 , $\mathrm{P}=0.01$ ). There was no difference between MG and US in specificity $(100 \%$ vs $99.9 \%, \mathrm{P}=0.51)$ and PPV (72.7\% vs $70.0 \% ; \mathrm{P}=0.87)$. US would cost approximately $\$ 20-30 \mathrm{USD}$ while MG cost $\$ 65-75$ USD. To detect one breast cancer, the costs of US, MG, and combined modality were $\$ 7876$, $\$ 45,253$, and $\$ 21,599$ USD, respectively [7]. Thus, although MG is still recommend as the initial/primary imaging test for breast cancer screening according to the Chinese AntiCancer Association Guidelines [25], US had been officially designated to be the initial imaging test for breast cancer screening in the national 'Two Cancer Screening' campaign in China [7, 26]. However, few studies had reported clinical and pathological features of US-detected NPBC as well as its long term survival prognosis.

Screen-detected breast cancers could occasionally be palpable in patients unaware of the symptom, however, most of the screen-detected cancers are NPBC in asymptomatic women. Although there are concerns about over-diagnosis of screen-detected NPBC based on natural history observation cohort study that some breast cancer might regress or never progress $[27,28]$, the association between screen-detected DCIS and subsequent invasive interval cancers suggests that detection and treatment of DCIS is still worthwhile in prevention of future invasive disease [29]. Currently the treatment strategy of NPBC is made according to palpable cancers of similar stage, subtype and grade [30]. Bae MS et al. reported comparison study between 807 MG-detected NPBC vs 256 US-detected NPBC [31]. However, the 807 (MG+/US not done) NPBC would include some MG+/US- NPBC and majority of $\mathrm{MG}+/ \mathrm{US}+\mathrm{NPBC}$ patients, while the 256 US-detected NPBC patients were all MG-/US+. Similarly in our study, there would also be $\mathrm{MG}+/ \mathrm{US}+$ double positive NPBC patients in the (US+/MG not done) group. Factors of early detection level such as $\mathrm{pT}$ and $\mathrm{pN}$ stage were identified as DFS predictors instead of factors revealing disease nature such as the molecular subtype. Laterality was also identified as DFS factors because the contralateral breast cancer might not be NPBC and thus affect the survival. Overall, US could detect more invasive, lymph node positive, low grade tumor, multifocal cancer and still the survival results showed no difference between US and MG detected NPBC. This might explained by the more intensive treatment. For example, there were significantly more US-NPBC patients received chemotherapy $(40.7 \%$ vs $21.3 \%$, p $<0.001)$.

There are several limitations in our study. Firstly, there is no uniform national breast cancer screening currently in China, and patients with positive US were screened by multi-modalities. So there was no data about the estimated 1.8-2.4 million women out of whom these NPBC patients were diagnosed. Secondly, there were NPBC patients detected by both US and MG who did not have dense breasts, and NPBC patients detected by US only but did not receive MG. These NPBC were all counted as US-NPBC, however, a small portion of these NPBC could also be visualized by MG. Thirdly, it seemed to make more sense to compare NPBC only detected by US versus NPBC only detected by MG. However, NPBC only detected by US but not by MG was difficult to identify and such comparison would exclude patients with dense breasts who did not receive mammogram. Fourthly, in our study cohort, there supposed to be more women with elevated risk such as family history of cancer, previous breast biopsy for benign diseases or hormone replacement therapy, and more women of more advantageous socioeconomic status and easy access to medical resources. This would result in selection bias. Last but not the least, it was a retrospective non-randomized single-center study with limited case number and follow-up time, so there were not enough OS events to identify OS prognostic factors.

In conclusion, our study revealed that compared to $\mathrm{MG}$, US could detect more invasive, node-positive, multifocal NPBC as initial screening test in hospitalbased asymptomatic Chinese women, who could achieve comparable 10-year DFS and OS of MG-detected NPBC. US would not delay the early detection of NPBC with improved cost-effectiveness, and thus could serve as the feasible primary imaging modality in hospital-based opportunistic screening among Chinese women.

\section{MATERIALS AND METHODS}

\section{Ethics statement}

This study was approved by the Ethics Committee of the Peking Union Medical College Hospital, Chinese Academy of Medical Sciences.

\section{Patient selection, pathology review and follow-up}

From January 2001 to December 2014, 4,574 asymptomatic patients with positive screening imaging US or MG (defined as BI-RADS 4 and 5) underwent biopsies 
in PUMC Hospital according to the medical records searching. These "screening positive" patients included self-referred women who came to PUMC Hospital, other hospitals or healthcare institutions in China for opportunistic screening and later came to the breast clinics in PUMC Hospital as "screening positive" for biopsy or surgery. Women enrolled in this study were all self-referred without randomization and asymptomatic without palpable breast mass or nipple discharge. Other "screening positive" patients were women enrolled in the community-based Two Cancer Screening Project in Beijing and in China [20, 21, 23] and transferred to PUMC Hospital with the positive finding. About $1 / 3$ of the patients were local from Beijing, and the other $2 / 3$ from other provinces in China. USguided biopsy was performed for the US positive patients, regardless of the result of mammogram while MG-guided biopsy was performed only for the MG-positive USnegative patients (Figure 1). 729 NPBC were diagnosed with 588 US-detected NPBC and 141 MG-detected NPBC out of a total 1.8-2.4 million asymptomatic women participated in the hospital-based screening estimated with the breast cancer incidence of 30-40/ten thousand in rural areas of China [2]. All NPBC patients' formalinfixed paraffin-embedded (FFPE) pathological sections were reviewed to confirm the diagnosis. All patients were followed by telephone call, by out-patient clinics records of follow-up examinations or by both measures. 30 patients including 16 US-NPBC and 14 MG-NPBC were excluded due to missing clinicopathological data. The clinicopathological characteristics, treatment choice, DFS and OS were compared between US-detected NPBC and MG-detected NPBC (Table 1) and the prognostic factors were identified respectively (Table 3, 4, Figure 2).

\section{Statistical analysis}

The quantitative variables were compared with t-test and the categorical variables were compared with chi-square tests. Survival outcomes including 10-year predicted DFS and OS were analyzed and compared by the Kaplan-Meier curve method. Kaplan-Meier univariate analyses and Cox multivariate analyses were performed to identify the DFS and OS prognostic factors for all NPBC, US-detected NPBC and MG-detected NPBC respectively. The significance threshold was set at $\mathrm{p}<0.05$. SPSS software, version 18.0 (SPSS, Inc. Chicago, IL, US) was used for all of the statistical analyses.

\section{ACKNOWLEDGMENTS}

We would like to thank all of the patients for their participation in this study.

\section{CONFLICTS OF INTEREST}

The authors have declared that no competing interests exist.

\section{FUNDING SUPPORT}

This work was supported by the Twelfth Five Year Key Programs for Science and Technology Development of China (Grant No. 2014BAI028B03), the Natural Science Foundation of China (Grant No. 81001183) and the Science \& Technology Research Project of Returned Visiting Scholar, Ministry of Human Resources and Social Security (2015).

\section{REFERENCES}

1. Fan L, Strasser-Weippl K, Li JJ, St Louis J, Finkelstein DM, Yu KD, Chen WQ, Shao ZM, Goss PE. Breast cancer in China. The Lancet Oncology. 2014; 15:e279-289.

2. Chen W, Zheng R, Baade PD, Zhang S, Zeng H, Bray F, Jemal A, Yu XQ, He J. Cancer statistics in China, 2015. CA: a cancer journal for clinicians. 2016; 66:115-132.

3. Stomper PC, D'Souza DJ, DiNitto PA, Arredondo MA. Analysis of parenchymal density on mammograms in 1353 women 25-79 years old. AJR American journal of roentgenology. 1996; 167:1261-1265.

4. Li J, Zhang BN, Fan JH, Pang Y, Zhang P, Wang SL, Zheng S, Zhang B, Yang HJ, Xie XM, Tang ZH, Li H, Li JY, et al. A nation-wide multicenter 10-year (1999-2008) retrospective clinical epidemiological study of female breast cancer in China. BMC cancer. 2011; 11:364.

5. Mandelson MT, Oestreicher N, Porter PL, White D, Finder CA, Taplin SH, White E. Breast density as a predictor of mammographic detection: comparison of interval- and screen-detected cancers. Journal of the National Cancer Institute. 2000; 92:1081-1087.

6. Checka CM, Chun JE, Schnabel FR, Lee J, Toth H. The relationship of mammographic density and age: implications for breast cancer screening. AJR American journal of roentgenology. 2012; 198:W292-295.

7. Shen S, Zhou Y, Xu Y, Zhang B, Duan X, Huang R, Li B, Shi Y, Shao Z, Liao H, Jiang J, Shen N, Zhang J, et al. A multi-centre randomised trial comparing ultrasound vs mammography for screening breast cancer in highrisk Chinese women. British journal of cancer. 2015; 112:998-1004.

8. Berg WA, Blume JD, Cormack JB, Mendelson EB, Lehrer D, Bohm-Velez M, Pisano ED, Jong RA, Evans WP, Morton MJ, Mahoney MC, Larsen LH, Barr RG, et al. Combined screening with ultrasound and mammography vs mammography alone in women at elevated risk of breast cancer. Jama. 2008; 299:2151-2163.

9. Berg WA, Zhang Z, Lehrer D, Jong RA, Pisano ED, Barr RG, Bohm-Velez M, Mahoney MC, Evans WP, 3rd, Larsen LH, Morton MJ, Mendelson EB, Farria DM, et al. Detection of breast cancer with addition of annual screening ultrasound or a single screening MRI to mammography in women with elevated breast cancer risk. Jama. 2012; 307:1394-1404. 
10. Nothacker M, Duda V, Hahn M, Warm M, Degenhardt F, Madjar H, Weinbrenner S, Albert US. Early detection of breast cancer: benefits and risks of supplemental breast ultrasound in asymptomatic women with mammographically dense breast tissue. A systematic review. BMC cancer. 2009; 9:335.

11. Crystal P, Strano SD, Shcharynski S, Koretz MJ. Using sonography to screen women with mammographically dense breasts. AJR American journal of roentgenology. 2003; 181:177-182.

12. Kolb TM, Lichy J, Newhouse JH. Comparison of the performance of screening mammography, physical examination, and breast US and evaluation of factors that influence them: an analysis of 27,825 patient evaluations. Radiology. 2002; 225:165-175.

13. Kolb TM, Lichy J, Newhouse JH. Occult cancer in women with dense breasts: detection with screening US-diagnostic yield and tumor characteristics. Radiology. 1998; 207:191-199.

14. Uchida K, Yamashita A, Kawase K, Kamiya K. Screening ultrasonography revealed $15 \%$ of mammographically occult breast cancers. Breast cancer. 2008; 15:165-168.

15. Berg WA, Bandos AI, Mendelson EB, Lehrer D, Jong RA, Pisano ED. Ultrasound as the Primary Screening Test for Breast Cancer: Analysis From ACRIN 6666. Journal of the National Cancer Institute. 2016; 108.

16. Mayor S. Ultrasound is similar to mammography in detecting breast cancer, study shows. Bmj. 2015; 351:h6925.

17. Benson SR, Blue J, Judd K, Harman JE. Ultrasound is now better than mammography for the detection of invasive breast cancer. American journal of surgery. 2004; 188:381-385.

18. Ohlinger R, Heyer H, Thomas A, Paepke S, Warm H, Klug U, Frese H, Schulz K, Schimming A, Schwesinger G, Kohler G, Wodny M, Kohlmann T, et al. Non-palpable breast lesions in asymptomatic women: diagnostic value of initial ultrasonography and comparison with mammography. Anticancer research. 2006; 26:3943-3955.

19. Federation A-CWs. Rural Cervical and Breast Cancer Screening Project. http://wwwwomenofchinacn/ womenofchina/html1/source/glossary/17/4551-1htm; and http://wwwwomenofchinacn/womenofchina/html1/photos/ 1512/905-1htm. 2014.
20. China SCo. The arrangement of the "Two Cancer (breast and cervical cancer) Screening" from the State Council of China Chinese Primary Health Care. 2009; 10:52.

21. China NHaFPCo. Ministry of Health of China and AllChina Women's Federation (2009) Announcement and Protocol of the "Free Two Cancer (breast and cervical cancer) Screening" among rural Chinese women. http:// wwwnhfpcgoven/fys/s3581/201007/02a20b251ac646f289 6dbc0b71a2cf92shtml. 2010.

22. Song QK, Wang XL, Zhou XN, Yang HB, Li YC, Wu JP, Ren J, Lyerly HK. Breast Cancer Challenges and Screening in China: Lessons From Current Registry Data and Population Screening Studies. The oncologist. 2015; 20:773-779.

23. Bureau BMH. The hospitals and institutions for Two Cancer Screening Project in Beijing. http://wwwbjhbgoven/gzfwq/ wycx/lascjgcx/. 2014.

24. Molleran VM. Will supplemental screening ultrasound increase breast cancer overdiagnosis? Academic radiology. 2015; 22:967-972.

25. Chinese Anti-Cancer Association CoBCSC-C. Breast cancer diagnosis and treatment guidelines in China. 2015.

26. Federation MoHoCaA-CWs. The management protocol for breast cancer and cervical cancer in the 3-year national "Two Cancer Screening” campaign (2009-2011). 2009 June 24.

27. Zahl PH, Gotzsche PC, Maehlen J. Natural history of breast cancers detected in the Swedish mammography screening programme: a cohort study. The Lancet Oncology. 2011; 12:1118-1124.

28. Welch HG, Black WC. Overdiagnosis in cancer. Journal of the National Cancer Institute. 2010; 102:605-613.

29. Duffy SW, Dibden A, Michalopoulos D, Offman J, Parmar D, Jenkins J, Collins B, Robson T, Scorfield S, Green K, Hall C, Liao XH, Ryan M, et al. Screen detection of ductal carcinoma in situ and subsequent incidence of invasive interval breast cancers: a retrospective population-based study. The Lancet Oncology. 2016; 17:109-114.

30. Ahmed M, Douek M. The management of screen-detected breast cancer. Anticancer research. 2014; 34:1141-1146.

31. Bae MS, Han W, Koo HR, Cho N, Chang JM, Yi A, Park IA, Noh DY, Choi WS, Moon WK. Characteristics of breast cancers detected by ultrasound screening in women with negative mammograms. Cancer science. 2011; 102:1862-1867. 